\title{
Review: Bioremediasi Pencemaran Minyak Bumi
}

\author{
Dwi Nuryana \\ Jurusan Teknik Kimia, Fakultas Teknik, Universitas Negeri Semarang
}

\begin{abstract}
Abstrak
Pemanfaatan minyak bumi yang tidak memperhatikan kelestarian lingkungan akan merugikan manusia dan mengakibatkan pencemaran lingkungan, sehingga perlu dilakukan penanggulangan melalui pengelolaan dan pemanfaatan limbah dengan cara bioremediasi. Bioremediasi merupakan suatu proses pemulihan lahan yang tercemar dengan mengeksploitasi kemampuan mikroorganisme untuk mendegradasi senyawa-senyawa organik. Pemilihan mikroorganisme bioremediasi sangat berpengaruh terhadap proses degradasi minyak bumi. Hal tersebut dikarenakan setiap spesies mikroorganisme membutuhkan substrat yang spesifik untuk mendegradasi keseluruhan komponen penyusun minyak bumi. Perlu pendekatan lebih lanjut untuk mengetahui efektifitas metode bioremediasi dan mikroorganisme yang digunakan baik mikroorganisme yang diperoleh dari luar (nonindigenous) atau mikroorganisme lokal (indigenous) yang digunakan para peneliti dalam mendegradasi minyak bumi. Namun, tidak semua rangkuman jurnal yang ada menunjukkan informasi yang detail mengenai metode dan efektifitas mikroorganisme dalam bioremediasi. Dalam paper ini, akan dikaji beberapa metode dan mikroorganisme yang digunakan dalam bioremediasi, diantaranya biopile, bulking agent,ex-situ, konsorsium bakteri dan teknik land treatment sehingga dapat disimpulkan metode paling efektif dalam bioremediasi minyak bumi.
\end{abstract}

Keywords: bioremediasi, metode bioremediasi, efektifitas mikroorganisme, prospek biokompos dan biosurfaktan

Corresponding Author: dwi.nuryana@gmail.com

\section{PENDAHULUAN}

Limbah minyak bumi dapat terjadi di semua lini aktivitas perminyakan mulai dari eksplorasi sampai ke proses pengilangan dan berpotensi menghasilkan limbah berupa lumpur minyak bumi (oil sludge). Tumpahan tersebut merupakan polutan yang dapat mengganggu ekosistem pada wilayah yang terkontaminasi. Tanah yang tercemar limbah hidrokarbon akan membahayakan karena senyawa hidrokarbon bersifat toksik dan karsinogenik (Zam, 2011) sehingga dapat mematikan organisme-organisme yang terdapat di wilayah tersebut (Priadie, 2012).

Upaya yang dapat dilakukan untuk menganggulangi lingkungan yang tercemar minyak adalah dengan teknik bioremediasi, yaitu proses pemulihan lahan yang tercemar dengan mengeksploitasi kemampuan mikroorganisme untuk mendegradasi senyawa-senyawa organik (Marsandi, 2016). Pemilihan mikroorganisme bioremediasi sangat berpengaruh terhadap proses degradasi minyak bumi. Hal tersebut dikarenakan setiap spesies mikroorganisme membutuhkan substrat yang spesifik untuk mendegradasi keseluruhan komponen penyusun minyak bumi (Marsandi, 2016). Kesesuaian metode dan spesies mikroorganisme dapat meningkatkan degradasi minyak bumi sehingga menurunkan toksisitas limbah minyak bumi.

Dalam paper ini akan dikaji beberapa metode yang digunakan dalam bioremediasi, diantaranya biopile, bulking agent,ex-situ, konsorsium bakteri dan teknik land treatment sehingga dapat disimpulkan metode paling efektif dalam bioremediasi minyak bumi.

\section{BIOREMEDIASI DENGAN BERBAGAI METODE}

Ada beberapa metode dalam bioremediasi minyak bumi yaitu biopile, bulking agent, konsorsium bakteri dan teknik land treatment. Tulisan tentang berbagai metode bioremediasi terdapat pada Tabel 1. 
Dwi Nuryana /JEEE Vol. 6 No. 2/2017

Table 1. Metode, Bahan, Mikroorganisme, dan Hasil Bioremediasi

\begin{tabular}{|c|c|c|c|c|c|}
\hline No & Motode & Bahan & Mikroorganisme & Hasil & Referensi \\
\hline 1. & Biopile & Pasir dan tanah & Isolat KBTL1, KBTL2, KBTL3 & $\begin{array}{l}\text { Menurunkan TPH dari } \\
4,22 \% \text { jadi } 1 \% \text { dalam } 63 \\
\text { hari } \\
\text { Populasi bakteri } 1 \times 10^{6} \\
\text { sampai } 1,43 \times 10^{11} \mathrm{CFU} / \mathrm{g}\end{array}$ & $\begin{array}{l}\text { Arifudin } \\
\text { dkk., } 2016\end{array}$ \\
\hline 2. & $\begin{array}{l}\text { Bulking agent dan } \\
\text { isolasi bakteri } \\
\text { pertofilik }\end{array}$ & Serbuk gergaji & $\begin{array}{l}\text { Pseudomonas sp. (PSP01) } \\
\text { Pseudomonas sp. (PSP 05) } \\
\text { Bacillus sp. (PSP 03) }\end{array}$ & $\begin{array}{l}\text { Menurunkan TPH sebesar } \\
\text { 91,04\% selama } 6 \text { minggu } \\
\text { Menurunkan BTEX si } \\
\text { bawah baku mutu } \\
\text { lingkungan }\end{array}$ & $\begin{array}{l}\text { Munawar } \\
\text { dan Zaidan, } \\
2013\end{array}$ \\
\hline 3. & $\begin{array}{l}\text { Bulking agent dan } \\
\text { isolasi bakteri } \\
\text { pertofilik }\end{array}$ & $\begin{array}{l}\text { Arang sekam padi } \\
\text { dan baglog jamur } \\
\text { tiram }\end{array}$ & $\begin{array}{l}\text { Pseudomonas sp. } \\
\text { Actinomycotes sp. }\end{array}$ & $\begin{array}{l}\text { Nilai efisiesnsi } \\
\text { biodegradasi mencapai } \\
83,9 \%\end{array}$ & $\begin{array}{l}\text { Zulkifliani, } \\
2016\end{array}$ \\
\hline 4. & $\begin{array}{l}\text { Bulking agent dan } \\
\text { isolasi bakteri } \\
\text { pertofilik }\end{array}$ & $\begin{array}{l}\text { Kompos iradiasi, } \\
\text { serbuk gergaji, } \\
\text { sludge biogas, } \\
\text { kompos }\end{array}$ & $\begin{array}{l}\text { Aspergillus niger } \\
\text { Trichoderma zeanum } \\
\text { Bacillus sphaericus } \\
\text { Pseudomonas aeruginosa }\end{array}$ & $\begin{array}{l}\text { Penurunan TPH } 81,32 \% \\
\text { selama } 42 \text { hari } \\
\text { Degradasi distribusi rantai } \\
\text { C-7 sampai C-54 jadi C-6 } \\
\text { sampai C-8 }\end{array}$ & $\begin{array}{l}\text { Tri Retno } \\
\text { dkk, } 2013\end{array}$ \\
\hline 5. & $\begin{array}{l}\text { Konsorsium } \\
\text { bakteri }\end{array}$ & Lamtoro & $\begin{array}{l}\text { Pseudomonas pseudoalcaligenes } \\
\text { Micrococus luteys }\end{array}$ & $\begin{array}{l}\text { Penurunan TPH 2,85 } \\
\text { selama } 14 \text { hari }\end{array}$ & $\begin{array}{l}\text { Marsandi } \\
\text { dan } \\
\text { Estuningsih, } \\
2016\end{array}$ \\
\hline 6. & $\begin{array}{c}\text { Konsorsium } \\
\text { bakteri }\end{array}$ & & Isolasi bakteri indigen & Penurunan TPH 1,62\% & $\begin{array}{l}\text { Alghafari } \\
\text { dkk., } 2015\end{array}$ \\
\hline 7. & $\begin{array}{l}\text { Bioremediasi ex- } \\
\text { situ }\end{array}$ & $\begin{array}{l}\text { Tanah } \\
\text { terkontaminasi } \\
\text { minyak bumi }\end{array}$ & $\begin{array}{l}\text { Bacillus cereus } \\
\text { Pseudomonas putida } \\
\text { Rhodococcus erythropolis }\end{array}$ & $\begin{array}{l}\text { Penurunan } 97,5 \% \text { total } \\
\text { degradasi selama } 56 \text { hari } \\
\text { Kadar BTX } 6,4338 \mu \mathrm{g} / \mathrm{g}\end{array}$ & Maria, 2017 \\
\hline 8. & Land farming & - & $\begin{array}{l}\text { Bacillus (strain 3,3 dan 6,9) } \\
\text { Pseudomonas (strain 3,4) } \\
\text { Enterobacter (strain P6) } \\
\text { Strain tak teridentifikasi (strain P2) }\end{array}$ & $\begin{array}{l}\text { Penurunan TPH 5,8\% jadi } \\
2,8-3,2 \% \text { selama } 12 \\
\text { minggu (tanpa bahan } \\
\text { organik) } \\
\text { Penurunan TPH 5,8\% jadi } \\
<1 \% \text { setelah } 5 \text { minggu } \\
\text { (dengan bahan organik) }\end{array}$ & $\begin{array}{l}\text { Prayitno, } \\
2017\end{array}$ \\
\hline 9. & $\begin{array}{l}\text { Bioremediasi in- } \\
\text { vitro }\end{array}$ & $\begin{array}{l}\text { Limbah minyak } \\
\text { bumi pengilangan di } \\
\text { Sungai Pakning }\end{array}$ & $\begin{array}{l}\text { Acinetobacter baumannii, } \\
\text { Alcaligenes eutrophus, } \\
\text { Bacillus sp1., Methylococcus } \\
\text { capsulatus, Bacillus sp2., } \\
\text { Morococcus sp., } \\
\text { Pseudomonas diminuta, } \\
\text { Xanthomonas albilineans, } \\
\text { Bacillus cereus dan } \\
\text { Flavobacterium } \\
\text { branchiophiia }\end{array}$ & $\begin{array}{l}\text { Degradasi TPH } 73,241 \% \\
\text { selama } 7 \text { minggu } \\
\text { Penurunan COD 86,282\% } \\
\text { Laju pertumbuhan } \\
\text { 0,0446/jam }\end{array}$ & Zam, 2011 \\
\hline
\end{tabular}


Dwi Nuryana /JEEE Vol. 6 No. 2/2017

\section{Biopile}

Biopile merupakan salah satu teknik bioremediasi tanah tercemar minyak bumi dengan biaya pengolahan relatif rendah dan ramah lingkungan (Arifudin, 2016). Kelebihan teknik biopile antara lain tidak memerlukan lahan yang luas dan dapat dilakukan proses aerasi sehingga pertumbuhan dan aktivitas bakteri agen bioremediasi dapat terjaga (Diplock et al., 2010). Tipe ini dilakukan dengan mengalirkan oksigen untuk aerasi melalui pipa. Oksigen digunakan bakteri untuk proses metabolisme hidrokarbon. Distribusi oksigen dalam biopile akan terhambat bila tanah yang diolah bertekstur klei. Pada kelembaban tinggi tanah bertekstur klei sulit mengalirkan udara sehingga distribusi nutrisi dalam tanah tidak merata dan berdampak pada pertumbuhan dan aktivitas bakteri pendegradasi (Charlena et al. 2010) sedangkan tekstur tanah berubah kering ketika kelembaban berkurang (Arifudin, 2016). Penambahan pasir dapat meningkatkan porositas dan aerasi tanah. Untuk meningkatkan kegemburan dan kemampuan tanah dalam menahan air dapat ditambahankan kompos. Metode ini memiliki kelemahan berupa laju aliran yang terbatas melalui tanah (Arifudin, 2016). Berdasarkan penelitian Arifudin (2016), tipe biopile mampu menurunkan TPH (Total Petroleum Hydrocarbon) dari 4,22\% menjadi 1\% dalam 63 hari serta meningkatkan populasi bakteri dari $1 \times 10^{6}$ menjadi $1,43 \times 10^{11} \mathrm{CFU} / \mathrm{g}$.

\section{Bulking agent dan isolasi bakteri petrofilik}

Menurut Imaddudin (2011) penggunaan bulking agent dalam sistem pengolahan tanah bertujuan untuk menjaga porositas tanah, kelembaban, dan merupakan sumber nutrisi di dalam tanah. Bahan dasar untuk bahan bulking agent yang mudah ditemukan di alam adalah limbah sekam padi, kompos dan serbuk gergaji. Hasil isolasi dari lokasi limbah sludge minyak sudah teradaptasi dengan kondisi lingkungan dan karakteristik limbah sludge sehingga potensi kinerja biodegradasinya lebih efektif jika dibandingkan dengan agen biologis komersial yang belum sesuai dengan lingkungan limbah yang diolah (Thouand et al., 1999; Zhu et al., 2004). Hasil penelitian Munawar (2013) menyatakan terjadi penurunan TPH sebesar 91,04\% selama enam minggu. Bakteri total selama broses bioremediasi berkisar $10^{3} \mathrm{hingg} 10^{8} \mathrm{CFU} / \mathrm{g}$ tanah. Selain itu pada akhir pengamatan menunjukkan bahwa senyawa aromatik toksik BTEX sudah menunjukkan konsentrasi di bawah baku mutu lingkungan yang berlaku.

Pertumbuhan mikroba petrofilik dapat didukung oleh penggunaan agen biosurfaktan dalam proses biodegradasi limbah minyak bumi yang berfungsi untuk mengurangi ketegangan antar muka antara minyak dan air ( Veter et al. 2001). Bioagent dapat meningkatkan kepadatan populasi mikroba petrofilik saat proses bioremediasi dilakukan. Zulkifliani (2016) melakukan konsorsium petrofilik (Pseudomonas sp. Actinomycotes sp. dan jamur petrofilik) dan Azotobacter vinelandii (biosurfaktan), serta penggembur (arang sekam padi dan limbah baglog jamur tiram) dan menghasilkan nilai efisiensi biodegradasi mencapai 83,9\%.

Retno (2013) memperoleh kondisi optimal pada remediasi cemaran oil sludge 20\% menggunakan perlakuan penambahan konsorsia inokulum mikroba berbasis kompos iradiasi dalam 30\% serbuk gergaji (bulking agent) pada konsentrasi tanah 50\% dengan efisiensi degradasi TPH optimal sebesar 81,32\% selama 42 hari. Selain itu diperoleh degradasi distribusi rantai karbon C-7 sampai C-54 menjadi hidrokarbon dengan distribusi rantai C-6 sampai C-8.

\section{Konsorsium bakteri}

Penggunaan konsorsium bakteri pada proses bioremediasi minyak bumi dapat mempengaruhi proses degradasi minyak bumi. Hal tersebut disebabkan setiap spesies bakteri membutuhkan substrat yang spesifik untuk mendegradasi keseluruhan komponen penyusun minyak bumi (Marsandi, 2016). Menurut Yeung et al (1997) bahwa tanaman-tanaman dapat meningkatkan proses degradasi oleh mikroba dengan memberikan oksigen dalam area akar sepanjang saluran akar dan memperbesar pori-pori tanah. Inokulasi bakteri Micrococus luteus dan Pseudomonas pseudoalcaligenes dan penanaman lamtoro menghasilkan rata-rata jumlah sel bakteri tertinggi setiap minggunya, pertambahan berat basah tertinggi mencapai 9,67 $\pm 2,357$ dan penurunan rata-rata nilai TPH tertinggi yaitu sebesar $2,85 \%$. 
Dwi Nuryana /JEEE Vol. 6 No. 2/2017

\section{Bioremediasi ex-situ}

Pengambangan metode ex situ dengan slurry bioreactor berhasil diterapkan oleh (Ayotamuno dkk., 2007; Maria, 2017) pada degradasi lumpur minyak. Maria (2017) selama 56 hari total degradasi terbaik pada bioreaktor dengan penambahan 17,5\% Pseudomonas putida yang menghasilkan 97,5\% total degradasi dimana kadar akhir BTX diperoleh $6,4338 \mu \mathrm{g} / \mathrm{g}$.

\section{Landfarming}

Teknik landfarming memiliki keunggulan dibandingkan teknik ex situ lainnya yaitu proses yang digunakan lebih sederhanadan murah, dengan tingkat penghilangan yang tinggi. Namun teknik ini memiliki kelemahan yaitu membutuhkan lahan yang luas (Maila, 2004). Kondisi lingkungan untuk mendukung proses degradasi senyawa hidrokarbon oleh mikroba eksogen dalam teknik landfarming perlu diatur sedemikian sehingga cemaran minyak dapat dihilangkan dengan efektif. Hasil percobaan tanpa bahan organik menghasilkan penurunan nilai TPH dari 5,8 menjadi 2,8-3,2\% setelah 12 minggu. Hal ini menyatakan bahwa pemberian konsorsium dan dosis konsorsium bakteri tidak berpengaruh nyata terhadap penurunan nilai TPH maupun populasi mikroba tanah. Pada percobaan menggunakan bahan organik, kedua konsoesium bakteri dapat menurunkan TPH di bawah 1\% setelah 5 minggu percobaan.

\section{Bioremediasi in-vitro}

Secara alami mikroorganisme memiliki kemampuan untuk mengikat, mengemulsi, menstrasnpor, dan mendegradasi senyawa hidrokarbon menjadi lebih pendek dengan melibatkan enzim. Bakteri hidrokarbonoklastik memiliki potensi genetik untuk mengikat, mengemulsi, dan mendgradasi hidrokarbon. Konsentrasi $\mathrm{pH} 7,5$ memberikan hasil bioremediasi terbaik dengan melihat tingkat dgradasi TPH 73,241\% dan penurunan COD 86,283\% serta memiliki laju pertumbuhan 0,0446/jam (Zam, 2011).

\section{KESIMPULAN}

Setiap metode bioremediasi memiliki kelebihan, kekurangan dan efektifitas degradai masing-masing, namun terdapat beberapa metode yang menghasilkan penurunan TPH cukup tinggi yaitu dengan menambahkan biosurfaktan, bahan organik, bulking agent, serta konsorsium mikroba sehingga mikroorganisme dapat bekerja dengan optimal.

\section{DAFTAR PUSTAKA}

Alghifari, A., Estuningsih, S. P., \& Tanzerina, N. (2016). Konsentrasi Sludge Minyak Bumi dalam Proses Bioremediasi Memanfaatkan Bakteri Indigen dan Lamtoro Gung. Jurnal Lahan Suboptimal, 4(1), 31-37.

Arifudin, A., Yani, M., \& Murtilaksono, K. (2016). BIOREMEDIASI TANAH BERTEKSTUR KLEI TERKONTAMINASI MINYAK BUMI: APLIKASI TEKNIK BIOPILE DENGAN PENAMBAHAN PASIR. Jurnal Pengelolaan Sumberdaya Alam dan Lingkungan (Journal of Natural Resources and Environmental Management), 6(1), 13.

Charlena, Z. M. Alim, I. Anas, Y. Setiadi, M. Yani, 2010. Produksi gas karbon dioksida selama proses bioremediasi limbah heavy oil dengan teknik landfarming. Chem. Prog. 3(1), pp. 1-5

Diplock EE, Mardlin DP, Killham KS \& Paton GI, 2010. The Role of Decision Support for Bioremediation Strategies, Exempli fi ed by Hydrocarbons for In Site and Ex Situ Procedures. Pp 201-217 in Cummings SP (ed) Bioremediation Methods and Protocols. New York: Humana Press

Larasati, T. R. D., \& Mulyana, N. (2016). Bioremediasi Lahan Tercemar Limbah Lumpur Minyak Menggunakan Campuran Bulking Agents yang Diperkaya Konsorsia Mikroba Berbasis Kompos Iradiasi. Jurnal Ilmiah Aplikasi Isotop dan Radiasi, 9(2).

Imaddudin, F., 2011. Hubungan Antara Laju Konsentrasi Oil and Grease dan Bulking Agent (Sekam Padi dan Bintaro) pada proses Bioremediasi. Teknik Sipil dan Lingkungan, Institut Pertanian Bogor. Bogor. 
Maila, M.P., and Cloete, T.E., (2004), Bioremediation of petroleum hydrocarbons through landfarming: Are simplicity and costeffectiveness the only advantages?. Rev. Environ. Sci. Biotechnol. 3: 349-360

Marsandi, F., \& Estuningsih, S. P. (2016, November). Asosiasi Konsorsium Bakteri Pseudomonas Pseudoalcaligenes dan Micrococus Luteus dengan Lamtoro (Leucaena Leucocephala (Lamk.) De Wit) dalam Upaya Meningkatkan Bioremediasi Minyak Bumi. In Prosiding Seminar Biologi (Vol. 13, No. 1, pp. 807813).

Munawar, M., \& Zaidan, Z. (2016). Bioremediasi Limbah Minyak Bumi dengan Teknik Biopile di Lapangan Klamono Papua. Sains \& Matematika, 1(2).

Ole, M. A. N. (2017). Bioremediasi Benzene, Toluene, Dan Xylene (BTX) Dari Lahan Terkontaminasi Minyak Bumi Oleh Bakteri Aerobik Pada Fase Slurry Dalam Bioreaktor (Doctoral dissertation, Institut Teknologi Sepuluh Nopember).

Priadie, B. (2012). Teknik bioremediasi sebagai alternatif dalam upaya pengendalian pencemaran air. Jurnal ilmu lingkungan, 10(1), 38-48.

Prayitno, J. (2017). Ujicoba Konsorsium Mikroba dalam Upaya Bioremediasi Tanah Tercemar Minyak Dengan Menggunakan Teknik Landfarming Skala Bangku. Jurnal Teknologi Lingkungan, 18(2), 208-215.

Thouand G, Bauda P, Oudot J, Kirsch G, Sutton C, \& Vidalie JF, 1999. Laboratory evaluation of crude oil biodegradation with commercial or natural microbial inocula. Can. J. Microbiol; 45: 106-115.

Vidali, M. 2001. Bioremediation. an overview. Pure Applied Chem. 73 (7) pp. 63-172

Zulkifliani, Z., Suryatmana, P., Sylvia, A. R., \& Syafrizal, S. (2017). Effects of Petrofilic Microorganisms and Bulking Agent on Hydrocarbon's Biodegradation Efficiency. Scientific Contributions Oil and Gas, 39(3).

Zam, S. I. (2011). Bioremediasi Tanah Yang Tercemar Limbah Pengilangan Minyak Bumi Secara In Vitro Pada Konsentrasi pH Berbeda. Jurnal Agroteknologi, 1(2), 1-8. 